\title{
ESTUDO DO ESCOAMENTO SUPERFICIAL NA BACIA HIDROGRÁFICA DO RIO IVAÍ, PARANÁ, BRASIL
}

\section{STUDY OF OVERLAND FLOW IN THE IVAÍ RIVER BASIN, PARANÁ, BRAZIL}

\begin{abstract}
Manoel Luiz dos Santos
Universidade Estadual de Maringá /GEMA - Grupo de Estudos Multidisciplinares do Ambiente, Av. Colombo, 5790, bloco 24, Maringá, PR, Brasil - CEP 87020-900. E-mail: mldsantos@uem.br

Eduardo Souza de Morais Universidade Estadual de Maringá /GEMA - Grupo de Estudos Multidisciplinares do Ambiente, Av. Colombo, 5790, bloco 24, Maringá, PR, Brasil - CEP 87020-900.

E-mail: moraiseduardo@hotmail.com
\end{abstract}

Hélio Silveira

Universidade Estadual de Maringá /GEMA - Grupo de Estudos Multidisciplinares do Ambiente, Av. Colombo, 5790, bloco 24, Maringá, PR, Brasil - CEP 87020-900.

E-mail: hesilveira70@hotmail.com

Fabio Corrêa Alves

Universidade Estadual de Maringá /GEMA - Grupo de Estudos Multidisciplinares do Ambiente, Av. Colombo, 5790, bloco 24, Maringá, PR, Brasil - CEP 87020-900. E-mail: alves.fabioc@gmail.com

Informações sobre o Artigo

Data de Recebimento:

$02 / 04 / 2012$

Data de Aprovação:

$06 / 11 / 2013$

\section{Palavras-chave:}

Processos superficiais; bacia de drenagem; modelagem do escoamento superficial.

\section{Keywords:}

Surface processes; hidrography basin; overland flow modeling.

\begin{abstract}
Resumo
Mediante a aplicação da equação proposta por Kirby (1976), aliada a levantamento das variáveis físicas da bacia do Ivaí - PR, este trabalho se propõe a analisar o comportamento do escoamento superficial nessa importante bacia hidrográfica do estado do Paraná. Para tanto, foram levantadas as variáveis precipitação média anual, precipitação média por evento, capacidade de campo dos solos e evapotranspiração. Essas variáveis foram espacializadas e analisadas com o suporte das características geológicas, geomorfológicas, pedológicas e climáticas da bacia hidrográfica. O resultado da análise foi integrado, em ambiente digital, em um Sistema de informação Geográfica, fornecendo uma carta síntese das taxas de escoamento superficial da bacia. O resultado mostra que no curso inferior da bacia hidrográfica, região do Arenito Caiuá (Kr), ocorrem as maiores taxas de escoamento superficial da bacia. Tal fato é atestado pela agressiva erosão que sofrem os solos desenvolvidos sobre esse arenito na região Noroeste do estado do Paraná.
\end{abstract}




\begin{abstract}
Through the application of the equation proposed by Kirby (1976) combined with a survey of the physical variables of the Ivai basin, this work analyzes the behavior of the overland flow in this important hidrography basin in the state of Paraná. For such, we identified the variables of mean annual rainfall, average rainfall per event, field capacity of soils and evapotranspiration. These variables were spatialized and analyzed with the support of the geological, geomorphological, soil and climate characteristics of the basin. The result of the analysis was integrated in a Geographic Information System providing a synthesis map of runoff rates in the basin. The result shows that the lower reaches of the basin, in the Arenito Caiua $(\mathrm{Kr})$ region, the highest rates of overland flow in the basin can be observed despite having the lowest rates in annual precipitation. This fact is attested by the aggressive erosion suffered by soils developed on these lithologies in the northwestern region of the Paraná State.

aspects of some watersheds that contribute to Corumba IV hydroelectric power plant's reservoir, located in the city of Luziania, Goias state. The goal was identify the tendency to erosiveness and sediment delivery in selected watersheds that contribute to the reservoir based upon fluvial morphometric parameters. The study used Quick-Bird satellite's image and ortophotos obtained before the Corumba IV's power plant's reservoir overflow, as well as terrain numerical models (MNT), with topographic map and radar interferometry data from Shuttle Radar Topographic Mission (SRTM-NASA), along with the digital cartographic base and the geological map in the scale of 1:250.000. Geoprocessing algorithms were used within geographical information systems, ArcGis and Spring systems, to obtain linear, spatial and hypsometrics of the watersheds selected in the study, which provided an indication of prone areas to the occurrence of erosive processes and sediment delivery, usually magnified by human activities, mainly vegetation removal of soil surface, which may reduce the economic life span of the reservoir..
\end{abstract}

\section{Introdução}

O escoamento superficial ou escoamento direto é uma das principais variáveis que influenciam no regime hidrológico dos canais fluviais; é um dos principais modeladores do relevo, influenciando diretamente na produção de sedimentos em uma bacia hidrográfica e na agradação dos sistemas fluviais. O conhecimento das características do escoamento superficial de uma bacia hidrográfica é fundamental para a análise geoambiental da bacia e para a gestão dos seus recursos naturais.

Vários estudos que procuram modelar a produção de sedimentos da bacia hidrográfica passam também pela análise do escoamento superficial. Kirkby (1976) propõe uma série de equações que buscam quantificar a produção de sedimentos em uma bacia hidrográfica. Para isso se faz necessária a análise do comportamento do escoamento superficial da bacia; esse autor então propõe uma equação que leva em conta as características dos solos e o regime climático. Usando a equação proposta por Kirkby (op. cit.) aplicada a levantamento das variáveis físicas da bacia do rio Ivaí, este trabalho se propõe a analisar o comportamento do escoamento superficial nessa importante bacia hidrográfica do estado do Paraná.

\section{Área de estudo}

A bacia hidrográfica do rio Ivaí, PR é a segunda maior do estado, com uma área de $36.540,02 \mathrm{~km}^{2}$; apresenta uma ocupação e uso de solo diversificada. Porém destaca-se sua vocação eminentemente agrícola, com o plantio extensivo de soja, milho e cana de açúcar, e subordinadamente a pecuária. A rápida ocupação da bacia, a partir da década de 1940, promoveu intensa retirada da vegetação original, substituindo as florestas por campo agricola, de tal maneira que atualmente restam menos de 9\% de sua cobertura florestal original (Paiva, 2008; Leli, 2010). Esse fato alterou profundamente o comportamento do escoamento, tanto de superfície como de subsuperfície, como sugere o trabalho de Paiva (2008) acerca das alterações do fluxo de base na bacia hidrográfica.

O rio Ivaí é um dos principais tributários da margem esquerda do rio Paraná, no seu curso superior, desenvolve-se com um percurso de cerca de $680 \mathrm{~km}$ (Figura 1). Drena uma grande variedade de tipos litológicos e de solos e diferentes modelos de ocupação pioneira e variado comportamento climático. Sua nascente forma-se, na porção Sul do estado, pela união dos rios dos Patos e São João, na serra da Boa Esperança no Segundo Planalto paranaense, a mais de $800 \mathrm{~m}$ de altitude. Deságua no rio Paraná, no Noroeste do estado do Paraná, a uma altitude de $240 \mathrm{~m}$.

Para o estado do Paraná o rio Ivaí tem relevada importância em termos ambientais e socioeconômicos. A despeito disso, os estudos geomorfológicos e climatológicos são recentes, destacando-se os de Santos (1999), Andrade e Nery (2003), Destefani (2005), Biazin (2005), Baldo (2006), Kuerten (2006), Biazin e Santos (2008), Meurer (2008), Paiva (2008), Santos et al,(2008), Fugita (2009), Kuerten et al, (2009), Leli (2010), Leli et al. (2010), Santos et al, (2010). 


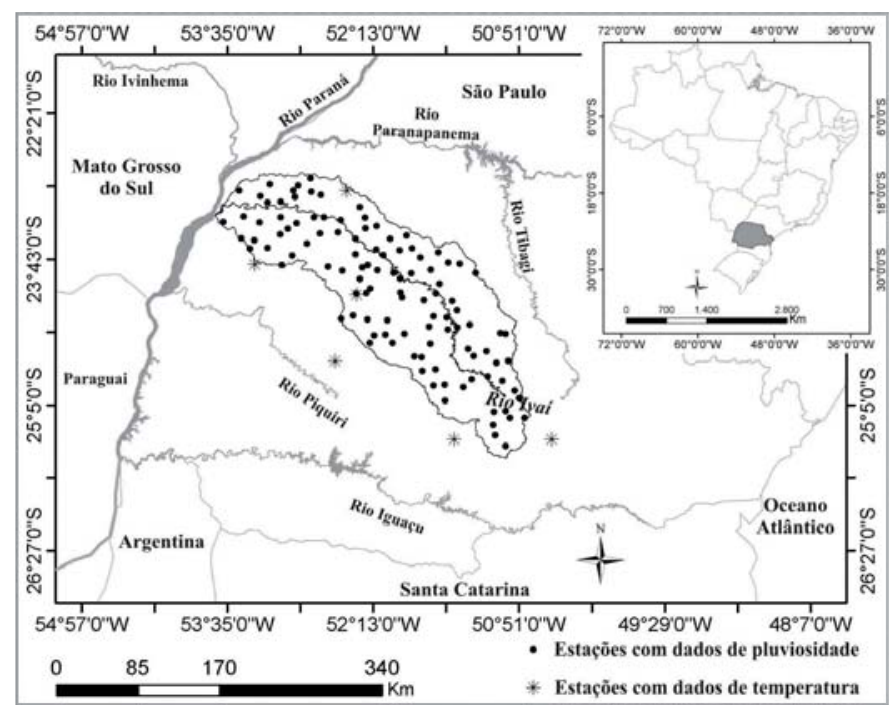

Figura 1 - Localização da bacia hidrográfica do rio Ivaí.

A bacia hidrográfica do rio Ivaí desenvolve-se sobre as litologias da Bacia Sedimentar do Paraná formadas entre os períodos Neo-Ordoviciano e Cretáceo. No setor superior da bacia hidrográfica, dominam as rochas sedimentares dos Grupos Passa Dois e São Bento; no seu setor médio dominam as rochas vulcânicas da Formação Serra Geral (J-Kr) e na porção inferior dominam os arenitos da Formação Caiuá (Kr) (Figura 2).

O rio Ivaí retrabalha sedimentos ao longo de seu curso e os deposita principalmente em seu curso inferior, onde desenvolve uma planície aluvial, formada ao longo do Quaternário, com cerca de $15 \mathrm{~km}$ de largura e $150 \mathrm{~km}$ de comprimento (Santos et al, 2008). Esse é o único trecho aluvial do rio, sendo que os cursos médio e superior se desenvolvem sobre leito rochoso (Santos, op. cit.).

O regime de débitos do rio Ivaí é caracterizado pela forte influência da precipitação e grande variação de nível. A vazão média histórica medida na estação fluviométrica de Novo Porto Taquara é de $727 \mathrm{~m}^{3} / \mathrm{s}$, sendo a média das cheias de $4019 \mathrm{~m}^{3} / \mathrm{s}$ e a vazão média das mínimas de $244,69 \mathrm{~m}^{3} / \mathrm{s}$ (Biazin, 2005; Leli, 2010).

A bacia hidrográfica abrange as unidades morfoesculturais do Segundo e Terceiro Planalto (Mineropar, 2006; Santos et al, 2006), sendo que cerca de $25 \%$ da área total da bacia está sobre o Segundo Planalto (setor superior), das nascentes do rio Ivaí até o início da cobertura Juro-Cretáceo de derrames basálticos. No Segundo Planalto dominam morros e escarpas de declividades acentuadas. No Terceiro Planalto, setor médio e inferior da bacia hidrográfica, as rochas vulcânicas basálticas da Formação Serra Geral dão origem a terrenos com topos alongados e vertentes em forma de cuestas e solos bem desenvolvidos como os Latossolos e Argissolos.

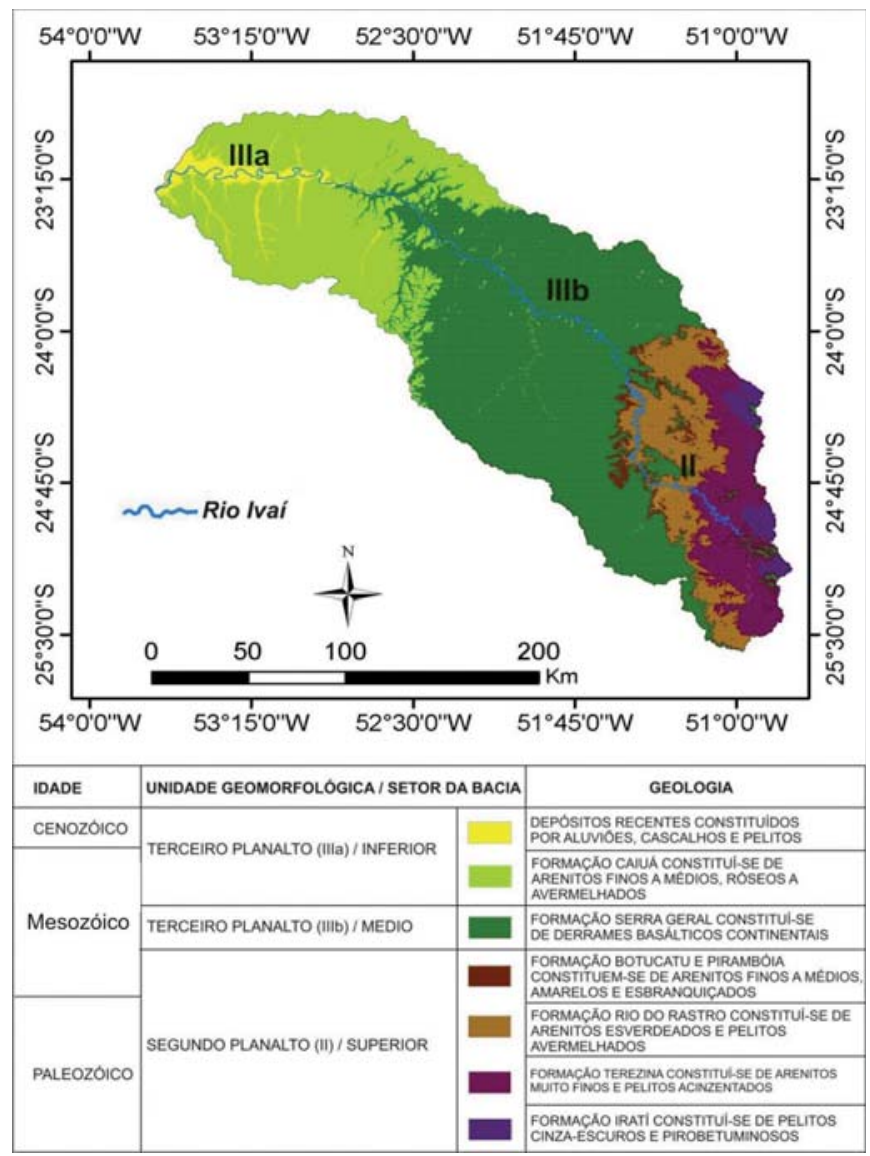

Figura 2 - Mapa Geológico / Geomorfológico da bacia hidrográfica do rio Ivaí. Fonte: Dados MINEROPAR (2000, 2006), Santos et al. (2006).

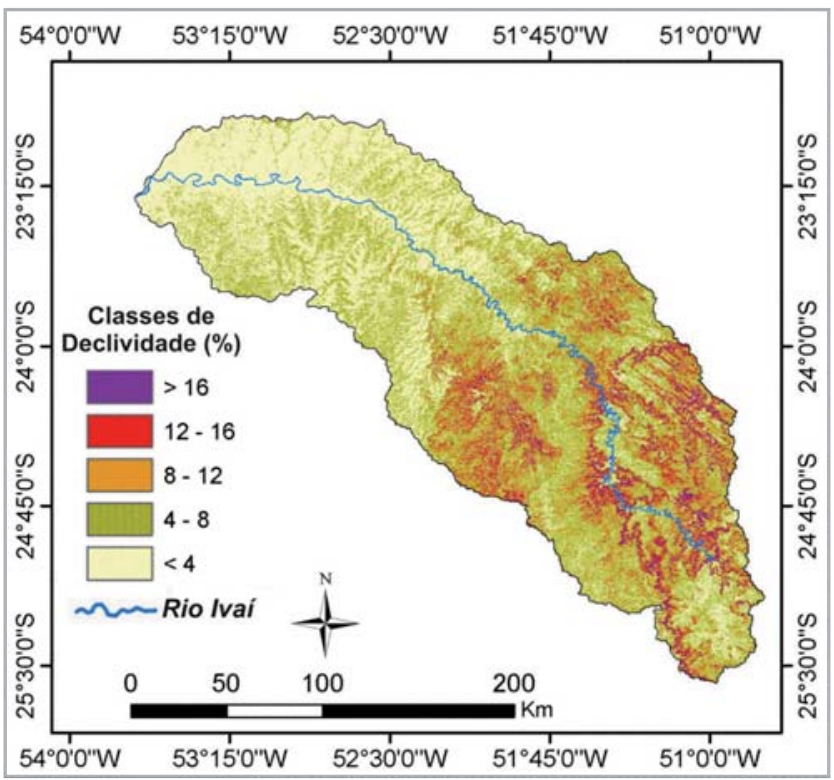

Figura 3 - Declividade da bacia hidrográfica do rio Ivaí. FONTE: Base: Dados SRTM (Shuttle Radar Topography Mission), Valeriano e Rossetti (2011). 
As maiores declividades estão no setor superior da bacia no Segundo Planalto e em setores restritos as cabeceiras de drenagens tributárias no Terceiro planalto, estas variam de $12 \%$ a mais de $16 \%$ (Figura 3 ). No setor inferior, na região da planície aluvial do rio Ivaí as declividades apresentam valores inferiores a $8 \%$. A planície aluvial é estreita e assimétrica, o canal fluvial é fortemente encaixado e apresenta um padrão meandriforme, controlado por alinhamentos tectônicos regionais (Santos et al., 2008).

\section{Metodologia}

O escoamento superficial pode ser compreendido como a água da precipitação que excede a capacidade de infiltração do terreno e/ou sua capacidade de armazenamento (Bridge, 2003, Knighton, 1998). Para a análise do escoamento superficial na bacia hidrográfica do rio Ivaí optou-se por usar o modelo de Kirkby (1976 e 1980). Esse autor propõe um modelo matemático para quantificar o escoamento superficial, levando em conta, além das características climáticas, a capacidade de armazenamento de água no solo (Equação 1).

Para a aplicação desse modelo, foram adotadas técnicas de geoprocessamento para que as variáveis analisadas pudessem ser espacializadas na bacia hidrográfica. Após a coleta e tabulação, os dados foram integrados no Sistema de Informação Geográfica Spring v.5.0.6. As variáveis que compõem as equações foram tratadas com a ferramenta Linguagem Espacial para Geoprocessamento Algébrico (LEGAL).

$$
O F=R e v^{-(r-h) / r}
$$

onde: a variável OF é o fluxo superficial (mm/ano); $R$ é a precipitação anual $(\mathrm{mm}) ; r_{c-} h$ é a capacidade de água disponível no solo( $\mathrm{mm})$; “ev" é a evapotranspiração anual $(\mathrm{mm}) ; r$ é a precipitação média por evento $(\mathrm{mm})$.

Foram utilizados cento e onze valores de precipitação pluviométrica do Paraná obtida por meio do banco de dados das estações pluviométricas do Instituto Nacional de Meteorologia (INMET) e do Instituto Agronômico do Paraná (IAPAR) no ano de 2009. A escolha deste ano se justifica uma vez que os dados de precipitação e temperatura foram os mais completos para os postos pluviométricos e estações climatológicas. As estações climatológicas dentro da bacia, além de poucas, não estão bem distribuídas na mesma. Portanto, usaram-se também dados de estações que, embora estivessem localizadas fora da bacia hidrográfica, não distassem mais de $100 \mathrm{~km}$ do limite da mesma. Portanto, neste trabalho, utilizaram-se valores de temperatura disponíveis em apenas seis estações climatológicas, para o ano de 2009, Tabela 1.

Para o cálculo de evapotranspiração potencial, foi necessária a utilização de valores de precipitação pluviométrica e temperatura. Por intermédio dos dados mensais de precipitação pluviométrica, temperatura, altitude e coordenadas geográficas do local estudado, foi calculado o balanço hídrico de acordo com Thornthwaite e Mather (1955), com auxílio de software desenvolvido por Rolim et al., (1998).

Os dados de precipitação pluviométrica e evapotranspiração potencial foram espacializados utilizando-se o método de interpolação por média simples disponível no software Spring. Este método sob análise estatística apresentou um menor Erro Quadrático Médio (EQM), melhor acurácia e veracidade com os valores em relação aos demais interpoladores, como demonstra o estudo realizado por Alves (2011). É interessante notar que os resultados visuais obtidos no produto final, também estão relacionados com a quantidade de amostras utilizadas neste processo e com o tipo de interpolador.

Tabela 1: Estações climatológicas com seus respectivos códigos, nomes, latitudes, longitudes, altitudes e período de análise - *INMET; ** IAPAR.

\begin{tabular}{|c|c|c|c|c|c|c|}
\hline $\mathbf{N}^{\circ}$ & Código & $\begin{array}{c}\text { Estaçăo } \\
\text { Climatolóqica }\end{array}$ & Lat. S. & $\begin{array}{l}\text { Long. } \\
\text { w. }\end{array}$ & $\begin{array}{l}\text { Alt. } \\
\text { (m) }\end{array}$ & Período \\
\hline 1 & 83783 & "Campo-Mourāo & $24^{\circ} 05^{\prime}$ & $52^{\circ} 37^{\prime}$ & 616 & \multirow{6}{*}{2009} \\
\hline 2 & 2550025 & $\begin{array}{l}\text { "Femandes } \\
\text { Pinheiro }\end{array}$ & $25^{\circ} 27^{\prime}$ & $50^{\circ} 35^{\prime}$ & 893 & \\
\hline 3 & 2551010 & "Guarapuava & $25^{\circ} 21^{\prime}$ & $51^{\circ} 30^{\prime}$ & 1058 & \\
\hline 4 & 2452050 & "Nova Cantu & $24^{\circ} 40^{\prime}$ & $52^{\circ} 34^{\prime}$ & 540 & \\
\hline 5 & 2352017 & "Paranavai & $23^{\circ} 05^{\prime}$ & $52^{\circ} 26^{\prime}$ & 480 & \\
\hline 6 & 2353008 & "Umuarama & $23^{\circ} 44^{\prime}$ & $53^{\circ} 17$ & 480 & \\
\hline
\end{tabular}

O mapeamento dos solos na área de estudo foi obtido a partir do levantamento de reconhecimento de solos do estado do Paraná (EMBRAPA, 1984), com a atualização para o novo sistema brasileiro de classificação de solos baseado na série de documentos $n^{\circ} 96$ (EMBRAPA, 2007). A base de apoio para o delineamento do mapa de solos em meio digital, foi obtida junto ao ITCG na escala 1:250.000, por meio do site eletrônico: http://www.itcg.pr.gov.br/. Esta base cartográfica foi posteriormente atualizada em ambiente SIG.

Os solos encontrados na área de pesquisa foram agrupados de acordo com as suas classes (Latossolos, Nitossolos, Cambissolos, Gleissolos, Neossolo Litólico, Neossolo Flúvico e Argissolos), e textura, que variou de média, argilosa, arenosa, arenosa/média e média/argilosa conforme mostra a Tabela 2. Após esse agrupamento, foram selecionados nos trabalhos de Costa (1989), Embrapa (1982a, 1982b), Fidalski e Tormena (2007) e Cavalieri et al., (2006) os valores de capacidade de água disponível (CAD) para os horizontes ou camadas superficiais (até $5 \mathrm{~cm}$ de profundidade), que mais se assemelhavam aos solos estudados neste trabalho. Esse procedimento se deu em razão da escala deste trabalho, da variabilidade da espessura dos solos ocorrentes na bacia e também pelo reduzido número de valores de CAD disponíveis na literatura para a bacia do rio Ivaí. 
Tabela 2: Classes de solos e capacidades de capacidade de água disponível (CAD), normalizada para $5 \mathrm{~cm}$ de profundidade.

\begin{tabular}{|l|l|}
\hline Classe de solo & CAD $(\mathrm{mm})$ \\
\hline Neossolo Flúvico textura arenosa & 3.35 \\
\hline Neossolo Flúvico textura argilosa & 2.30 \\
\hline Gleissolo textura argilosa & 12.08 \\
\hline Cambissolo textura argilosa & 5.20 \\
\hline Latossolo textura argilosa & 2.69 \\
\hline Latossolo textura média & 3.30 \\
\hline Argissolo textura arenosa/média & 1.95 \\
\hline Argissolo textura média/argilosa & 5.54 \\
\hline Neossolo Litólico textura média & 8.20 \\
\hline Neossolo Litólico textura argilosa & 8.40 \\
\hline Nitossolo & 6.05 \\
\hline
\end{tabular}

A carta de declividade foi gerada no ambiente Spring a partir de MDE do projeto Topodata, interpolados na resolução espacial de 30 metros, conforme descrito por Valeriano e Rossetti (2011). A distribuição dos declives da bacia hidrográfica foi analisada através da ferramenta Geoestatística, que considera os pontos presentes e informa a média de declive da área.

\section{Resultados e Discussões}

A distribuição espacial da pluviosidade dentro da bacia do rio Ivaí, para as escalas de análise (diária e mensal), apresentou um padrão com os valores mais elevados a montante, em virtude do efeito orográfico e do clima subtropical úmido predominante nessa porção, conforme também evidenciado por Baldo (2006). Já os menores valores pluviométricos foram observados a jusante, por estar numa área de baixas altitudes, numa faixa de transição do clima tropical.

Andrade (2002) e Baldo (2006) destacam as influências exercidas pelos fenômenos El Ninõ e La Ninã no comportamento pluviométrico da bacia do rio Ivaí. Nery et al. (1998) afirmam que o fenômeno ENOS (El Niño Oscilação Sul), exerce significativa influência na distribuição pluviométrica temporal, enquanto a orografia desempenha um papel de forçante da precipitação pluvial neste estado e no caso da bacia do Ivaí se manifesta principalmente na porção superior, onde os índices pluviométricos são maiores.

As Figuras 4a e 4b mostram a distribuição da precipitação e da evapotranspiração potencial na bacia hidrográfica do rio Ivaí. Nessas figuras pode ser observado que ocorre uma alteração no comportamento hídrico e térmico da parte superior da bacia (Segundo Planalto paranaense) para a parte inferior da mesma no Terceiro Planalto. No Segundo Planalto as precipitações observadas, tanto na série histórica como em 2009, são maiores do que as precipitações ocorrentes na região do Terceiro Planalto (acima de $2.051 \mathrm{~mm} / \mathrm{ano}$ ), no curso inferior da bacia hidrográfica (valores inferiores a $1.914 \mathrm{~mm} / \mathrm{ano})$.
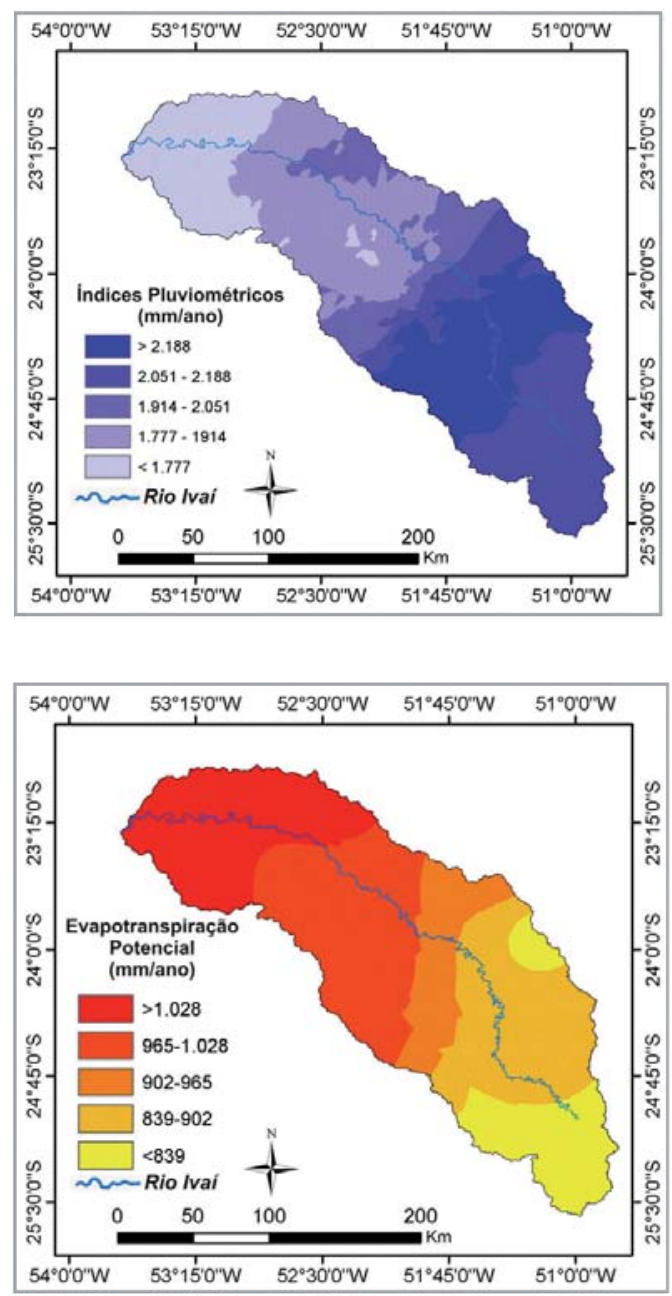

Figura 4 - (A, B) A-Distribuição da pluviosidade na bacia hidrográfica do rio Ivaí; B- Evapotranspiração potencial na bacia hidrográfica do rio Ivaí.

A evapotranspiração potencial é mais alta no setor jusante da bacia hidrográfica, em razão de as temperaturas médias serem maiores neste setor, com valores superiores a $1.028 \mathrm{~mm} /$ ano (Figura 4b), diminuindo em direção ao curso superior para valores menores que $902 \mathrm{~mm} /$ ano. Para Caramori (1988), os valores de evapotranspiração oferecem um grande subsídio para o dimensionamento de projetos de irrigação e drenagem, bem como para estudos de balanço hídrico. Nos estudos realizados pelo mesmo autor para o estado do Paraná foi possível dividir a bacia em dois setores, o primeiro com menos de $800 \mathrm{~mm} /$ ano na porção sul da bacia (Segundo Planalto) e o segundo entre 800 e $1.000 \mathrm{~mm} /$ ano na porção noroeste, no Terceiro Planalto paranaense, comprovando os resultados obtidos nesta pesquisa. 
A precipitação média por evento (razão entre a pluviosidade anual e o numero de dias de precipitação), mostrada na Figura 5, é maior para o curso inferior e médio da bacia do que para o curso superior, ou seja, ha maior concentração de precipitações nas áreas do curso médio e inferior da bacia, quando comparadas com o curso superior da mesma.

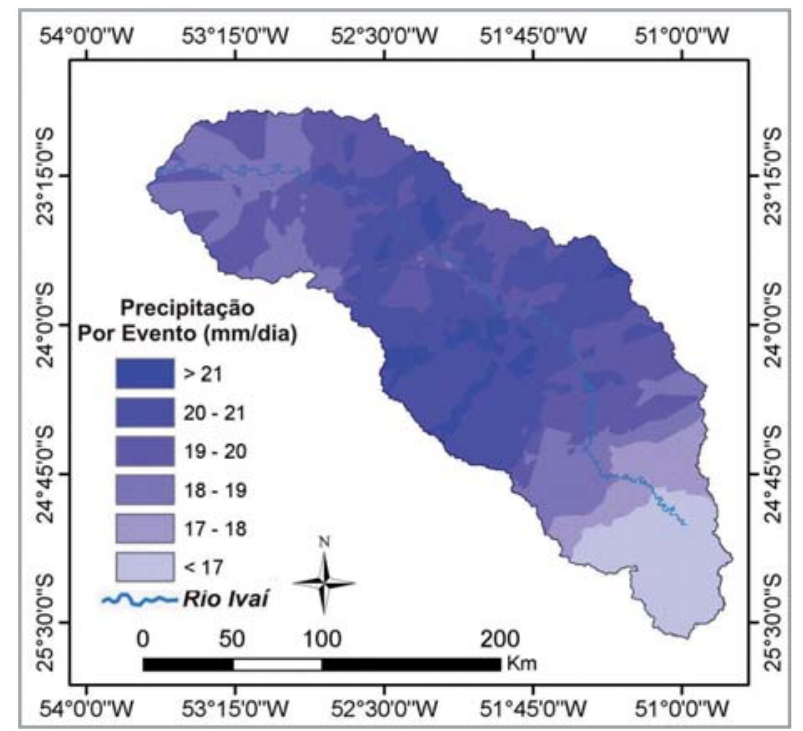

Figura 5 - Precipitação média por evento na bacia hidrográfica do rio Ivaí.

Para melhor discutir os dados encontrados, foi necessário caracterizar os solos de maior destaque espacial na bacia do rio Ivaí, juntamente com o relevo e a geologia, visando melhor compreender os resultados obtidos do escoamento superficial.

Os Latossolos são solos que apresentam espessura superior a $3 \mathrm{~m}$ de profundidade; são muito porosos, friáveis e ocorrem geralmente em áreas de relevo plano a suave ondulado onde a declividade varia de 0 a $8 \%$. Embora os Latossolos em geral sejam considerados como solos resistentes à erosão, principalmente os de textura argilosa, formados a partir da alteração do basalto da Formação Serra Geral, o mesmo não se pode afirmar para os Latossolos de textura média, oriundos da alteração do arenito da Formação Caiuá, Botucatu, Piramboia e Rio do Rastro (Figura 6).

Os Latossolos de textura média têm estrutura fracamente desenvolvida, sendo do tipo granular, com presença de grão simples no horizonte $\mathrm{A}$, onde os fenômenos erosivos são notórios, quer pela textura, quer pela estrutura ou pelo seu uso inadequado (EMBRAPA, 1984; FASOLO, 1988; OLIVEIRA et al., 1992).

Após o levantamento de dados e seu tratamento geoestatístico aplicados à equação Kirkby (1976), foi possível a geração do mapa síntese, demonstrando a distribuição do escoamento superficial na bacia hidrográfica analisada (Figura 7). Nessa Figura nota-se que o escoamento superficial é maior no curso inferior do rio Ivaí e em áreas mais restritas do curso médio e superior da bacia hidrográfica.

Grandes áreas do curso médio e superior são caracterizadas por um baixo valor de escoamento superficial, menor que $300 \mathrm{~mm} / \mathrm{ano}$. Nas áreas com o predomínio dos Latossolos de textura argilosa os valores e escoamento superficial variam de 600 a $900 \mathrm{~mm} /$ ano enquanto que nos setores onde houve ocorrência dos Latossolos de textura média o escoamento superficial está entre 300 a $600 \mathrm{~mm} / \mathrm{ano}$.

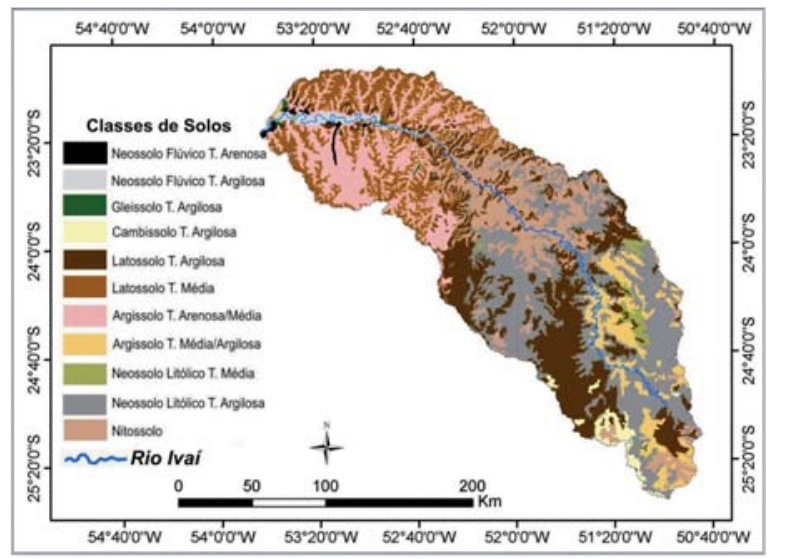

Figura 6 - Mapa de solos e de suas classes texturais na bacia hidrográfica do rio Ivaí

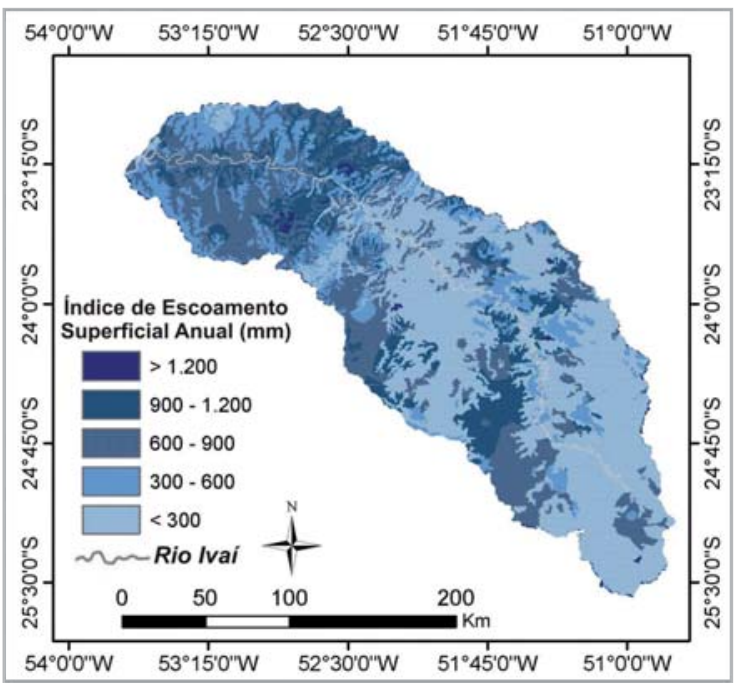

Figura 7 - Mapa Síntese do Escoamento Superficial na bacia Hidrográfica do rio Ivaí

Os Argissolos são solos profundos, com sequência de horizontes $\mathrm{A}, \mathrm{Bt}$ e $\mathrm{C}$, formados a partir da alteração de rochas sedimentares (arenito da Formação Caiuá, Botucatu, Piramboia e Rio do Rastro), particularmente (Figura 6). São encontrados ao longo da bacia em relevo suave ondulado e ondulado, onde as declividades variam de $8 \%$ a $20 \%$. A característica marcante desses solos é a diferença textural 
entre os horizontes A e E mais arenoso e o subsuperficial Bt, mais argiloso, como foi demonstrado nos trabalhos de (EMBRAPA, 1984; FASOLO, 1988; OLIVEIRA et al., 1992; CARVALHO, 1994).

Os valores de escoamento superficial encontrados nas áreas com Argissolos variam de 300 a 900 mm/ano e são mais elevados principalmente na região Noroeste do estado, onde ocorre o arenito da Formação Caiuá. Foi possível também observar que no curso inferior da bacia hidrográfica na região do arenito Caiuá onde são encontrados os Latossolos e Argissolos ocorre um aumento da precipitação por evento, muito embora se tenha uma menor taxa de precipitação anual, porém com menos dias de precipitações (precipitações mais concentradas), daí o maior escoamento de superfície ser bem evidenciado na Figura 7.

A veracidade dessa análise é atestada pela comum ocorrência de profundas voçorocas (com cerca de $30 \mathrm{~m}$ de profundidade), além de sulcos e ravinas, como as verificadas nos municípios de Umuarama, Cidade Gaúcha e Paranavaí, dentro da bacia estudada. Tal fato obriga a adoção de práticas de manejo adequadas para a conservação desses solos sobre o Arenito Caiuá e mitigação do efeito da erosão nesses municípios, como foi apontado por Bigarella e Mazuchowski (1985); Fasolo (1988); Souza et al., (2008); Nakashima (2000) e Carvalho (1994).

Os Neossolos litólicos são solos rasos com menos de $40 \mathrm{~cm}$ de espessura e estão assentados diretamente sobre a rocha ou sobre o horizonte $\mathrm{C}$ ou $\mathrm{Cr}$. $\mathrm{Na}$ bacia esses solos são formados a partir da alteração de diferentes materiais de origem, tais como de rochas eruptivas básicas, arenitos, siltitos e folhelhos pertencentes à Formação Serra Geral, Caiuá, Botucatu, Piramboia, Rio do Rastro, Terezina e Irati respectivamente (Figura 6). Ocorrem em sua grande maioria em locais de topografia acidentada, normalmente em relevo forte ondulado, montanhoso e até escarpado. Esses solos ocupam uma grande extensão espacial, principalmente nos setores médio e alto da bacia. Essa classe de solos em conjunto com os Cambissolos, apresentaram os menores valores de escoamento superficial, inferiores a $300 \mathrm{~mm} /$ ano (Figura 7).

Os Cambissolos encontrados em sua grande maioria têm textura argilosa e são formados a partir da alteração de basalto, argilito, siltito e folhelho (Figura 6). Esses solos têm espessura que variam de 50 a $130 \mathrm{~cm}$ e caracterizam-se pela presença de horizonte pouco evoluído, denominado de $\mathrm{B}$ incipiente. Na bacia do rio Ivaí, foram encontrados em relevo forte ondulado a montanhoso e devido a essa característica topográfica são muito susceptíveis à erosão, muito embora possam ser encontradas algumas manchas desse solo em relevo plano. Devido à sua variação de espessura, declividade e capacidade de água disponível (5,2 $\mathrm{mm}$ ), os valores de escoamento superficial revelaram-se inferiores a $300 \mathrm{~mm} / \mathrm{ano}$.
Para as áreas do Segundo Planalto e do curso médio da bacia hidrográfica onde se verificam os menores índices de escoamento superficial tem-se a ocorrência de maiores valores de capacidade de água disponível (Neossolos Litólicos - 8.2 a $8.4 \mathrm{~mm}$, Gleissolos - 12,08 mm e Cambissolos - $5.2 \mathrm{~mm}$, Tabela 2) e menores índices de precipitação por evento. Muito embora ocorram elevados valores de precipitação, que ultrapassam os $1.914 \mathrm{~mm}$ anuais. No modelo adotado o escoamento superficial é inversamente proporcional à razão entre capacidade de armazenamento de água no solo e precipitação média por evento isso explica os baixos valores de escoamento encontrados para essas classes de solos.

Os Organossolos são solos rasos normalmente encontrados em relevos planos, próximos as margens dos rios. São solos porosos que apresentam alta capacidade de armazenamento de água devido aos elevados teores de matéria orgânica. Na área deste estudo os Organossolos ocorrem em manchas muito reduzidas e estão associadas às áreas de ocorrência dos Gleissolos. Portanto em razão da escala deste trabalho e de sua localização geográfica eles estão inclusos dentro das áreas de menor escoamento superficial (menos de $300 \mathrm{~mm} / \mathrm{ano}$ ) e não podem ser individualmente representados.

\section{Conclusão}

Por intermédio da metodologia proposta por Kirkby (1976) aliada a técnicas de geoprocessamento foi possível a obtenção de um panorama geral do escoamento superficial na bacia hidrográfica do rio Ivaí.

A análise revela a aplicabilidade desse modelo para grandes áreas, a despeito de o mesmo não considerar o variável uso do solo e a declividade do terreno. Ressalta-se que os resultados observados podem ser diferentes se a base de dados levantada for aplicada a outras metodologias. Além disso, em razão da grande extensão da área de estudo, da pequena escala de trabalho e da espacialização restrita das estações climatológicas, as generalizações dos intervalos de escoamento superficial das águas foram inevitáveis.

A análise do escoamento superficial da bacia hidrográfica do rio Ivaí levou em conta somente as características climáticas e as características físicas dos solos. O resultado obtido pela aplicação da Equação de Kirkby (1976) revela uma grande coerência com os processos geomorfológicos verificados para essa região. As altas taxas de erosão verificadas no Terceiro Planalto paranaense, notadamente na região do Arenito Caiuá, e fartamente documentadas na literatura, evidenciam a importância do escoamento superficial na produção de sedimentos nessa área, fato este corroborado pelos resultados obtidos pela aplicação desta metodologia. 


\section{Agradecimentos}

Ao CNPq pelo apoio a esta pesquisa; ao Prof. Ms. Darlei Landi pelo auxílio na área de estatística e matemática utilizadas para o desenvolvimento deste trabalho. Finalmente o nosso agradecimento e nossa homenagem póstuma à Profa. Dra. Leonor Marcon, que nos auxiliou na obtenção dos dados climáticos junto ao INMET.

\section{Referências bibliográficas}

ALVES, F. C. Avaliação de interpoladores para a espacialização de variáveis de precipitação na bacia hidrográfica do rio Ivaí. In: SIMPÓSIO BRASILEIRO DE SENSORIAMENTO REMOTO, 15. (SBSR), 2011, Curitiba. Anais. São José dos Campos: INPE, 2011. p. 4070-4077.

ANDRADE, A.R. Variabilidade da precipitação pluviométrica da bacia hidrográfica do rio Ivaí-PR. 2002.99 p. Dissertação (Mestrado em Geografia), Universidade Estadual de Maringá UEM. Maringá, 2002.

ANDRADE, A.R.; NERY, J.T. Análise da precipitação pluviométrica diária, mensal e interanual da bacia hidrográfica do Rio Ivaí, Brasil. Investigaciones Geográficas, Boletín del Instituto de Geografía. UNAM, México, n. 52, p. 7-30, 2003.

BALDO, M.C. Variabilidade pluviométrica e a dinâmica atmosférica na bacia hidrográfica do rio Ivaí. 2006. 153p. Tese (Doutorado em Geografia), Universidade Estadual Paulista - UNESP. Presidente Prudente, 2006.

BIAZIN, P.C. Característica Sedimentar e Hidrológica do Rio Ivaí em sua Foz com o Rio Paraná, Icaraíma - PR. 2005. 70p. Dissertação (Mestrado em Análise Regional e Ambiental, Departamento de Geografia), Universidade Estadual de Maringá - UEM. Maringá, 2005.

BIAZIN, P.C.; SANTOS, M.L. Características geomórficas do canal e das formas de leito do rio Ivaí em seu curso inferior, Icaraíma PR. Revista Brasileira de Geomorfologia, v.9, n.1, p. 43-52, 2008.

BIGARELLA, J.J.; MAZUCHOWSKI, J.Z. Visão integrada da problemática da erosão. Livro Guia do $3^{\circ}$ Simpósio Nacional de controle de erosão, Maringá, ABGE, 1985. 331 p.

BRIDGE, J.S. Forms, processes, and sedimentary Record. Balckwell Publishing, 2003. 491p.

CARAMORI, P.H.; ARITA, C.A. Evapotranspiração potencial no Estado do Paraná segundo método de Penman. Boletim técnico. Londrina: IAPAR, n. 25, 1988. 44p.

CARVAlHO, A.P. de. Solos do arenito Caiuá. In: Solos altamente susceptíveis à erosão. FCAV-UNESP/SBCS, Jaboticabal, p. 39-50, 1994.

CAVALIERI, K.M.V.; TORMENA, C.A; VIDIGAL FILHO, P.S.; GONSALVES, A.C.A.; COSTA, A.C.S. Efeitos de sistemas de preparo nas propriedades físicas de um Latossolo vermelho distrófico. Revista Brasileira de Ciência do Solo, v. 30, n.1, p. 137-147, 2006.

COSTA, A.C.S. Caracterização físico-hídrica das principais unidades de solo. In: Potencial de uso agrícola das áreas da várzea do estado do Paraná. Boletim técnico. IAPAR, n. 24, v.1, set. 1989. p. 51-62.

DESTEFANI, E.V. Regime hidrológico do rio Ivaí - PR. 2005. 93p. Dissertação (Mestrado em Geografia), Universidade Estadual de Maringá - UEM. Maringá, 2005.

EMBRAPA. Disponibilidade de água de solos do norte de Minas Gerais, área de atuação da Sudene. Boletim de pesquisa. Rio de Janeiro: EMBRAPA/SNLCS, n.8, 1982a. 22p.

EMBRAPA. Curvas de retenção de umidade de solos do norte de Minas Gerais, área de atuação da Sudene. Boletim de pesquisa. Rio de Janeiro: EMBRAPA/SNLCS, n.4, 1982b. 19p.

EMBRAPA. Levantamento de reconhecimento dos solos do Estado do Paraná - tomo I e II. Boletim técnico. Londrina: EMBRAPA/SNLCS/IAPAR, 1984. 791p.

EMBRAPA. Manual de métodos de análise de solo. Rio de Janeiro, Centro Nacional de Pesquisa de Solos, 1997, 212p.

EMBRAPA. Mapa de Solos do Estado do Paraná. Boletim técnico. EMBRAPA/SNLCS d.96, 2007. 73 p.

FASOLO, P.J. Erosão: inventário de áreas críticas no Noroeste do Paraná. Boletim Técnico. Londrina: IAPAR/SEAB/SUDESUL, n 23, 1988. 20p.

FIDALSKI, J.; TORMENA, C.A. Funções de pedotransferência para as curvas de retenção de água e de resistência do solo à penetração em sistemas de manejo com plantas de cobertura permanente em citros. Ciência Rural, Santa Maria, v.37, n.5, p.1316-1322, 2007.

FUGITA, R.H. O Perfil Longitudinal do Rio Ivaí e sua Relação com a Dinâmica de Fluxos. 2009. 98p. Dissertação (Mestrado em Geografia) Universidade Estadual de MaringáUEM. Maringá, 2009.

KIRKBY, M.J. Hydrological slope models: the influence of climate. In: Derbyshire, E. Geomorphology and Climate. New York: John Wiley \& Sons, 1976. p. 247-267.

KIRKBY, M. J. Modeling water erosion processes. In: KIRKBY, M. J.; MORGAN, R. P. C. Soil erosion, New York: John Wiley \& Sons, 1980. p. 182-213.

KNIGHTON, D. Fluvial forms and process. Edward Arnold, 1998. $218 \mathrm{p}$.

KUERTEN, S. Variação longitudinal das características sedimentares e hidrológicas do rio Ivaí - PR em seu curso inferior. 2006. 97p. Dissertação (Mestrado em Geografia). Universidade Estadual de Maringá - UEM. Maringá, 2006. 
KUERTEN S.; SANTOS, M.L.; SILVA, A. Variação das características hidrosedimentares e geomorfologia do leito do Rio Ivaí - PR, em seu curso inferior. Revista Geociências, v 28 , n. 2 , p. $143-151,2009$.

LELI, I.T. Variação espacial e temporal da carga suspensa do rio Ivaí. 2010. 66p. Dissertação (Mestrado em Geografia), Universidade Estadual de Maringá - UEM. Maringá, 2010.

LELI, I.T.; STEVAUX, J.C.; NÓBREGA, M.T. Produção e Transporte da Carga Suspensa Fluvial: Teoria e Método para Rios de Médio Porte. Boletim de Geografia, v. 28, n.1, p. 4358. 2010 .

MINEROPAR. Atlas geológico do Estado do Paraná. Curitiba, CD-ROM, 2000.

MINEROPAR. Mapa Geomorfológico do Paraná, escala 1:250.000, Curitiba, CD-ROM, 2006.

MEURER, M. De L'hydro-écorégion au traçon fluvial: recherché méthodologigue. Le cas Du bassin versant L'Ivaí, EtadDu Paraná, Brésil. 2008. 307p. Tese de doutorado (Doctorat em Géographie, Aménagement et Urbanisme), Universté Lumière Lyon 2. Lyon, 2008.

NAKASHIMA, P. Sistema Pedológico da região noroeste do Estado do Paraná: distribuição e subsídios para o controle da erosão. 2000. 162p. Tese (Doutorado em Geografia) Departamento de Geografa, Universidade de São Paulo - USP. São Paulo, 2000.

NERY, J.T.; BALDO, M.C.; MARTINS, M.L.O.F. Variabilidade da Temperatura Mínima no Estado do Paraná. Revista Brasileira de Agrometeorologia, Santa Maria, RS, v. 6, n. 2, p. 207-212, 1998.

OLIVEIRA, J.B.; JACOMINE, P.K.T.; CAMARGO, M.N. Classes gerais de solos do Brasil: guia auxiliar para o seu reconhecimento. Jaboticabal-SP. FUNEP, 1992, 201p.

PAIVA, D.G. Análise do índice de relação entre o fluxo de base e desflorestamento por meio de imagens orbitais e análise hidrológica: Baixo curso do rio Ivaí - PR. 2008. 74p. Dissertação (Mestrado em Geografia), Universidade Estadual de Maringá-UEM. Maringá, 2008.
ROLIM, G.S.; SENTELHAS, P.C.; BARBIERI, V. Planilhas no ambiente EXCEL para os cálculos de balanços hídricos: normal, sequencial, de cultura e de produtividade real e potencial. Revista Brasileira de Agrometeorologia, Santa Maria, v.6, p.133-137, 1998.

SANTOS, I. Avaliação por perdas de solo por erosão hídrica na bacia do rio Ivaí. Anais do XII Simpósio Brasileiro de Recursos Hídricos. Belo Horizonte: 1999. 13 p.

SANTOS, L.J.C.; OKA-FIORI, C.; CANALI, N.E.; FIORI, A.P.; SILVEIRA, C.T.; SILVA, J.M.F.; ROSS, J.L.S. Mapeamento geomorfológico do Estado do Paraná. Revista Brasileira de Geomorfologia, ano 7, n. 2, p. 3-12, 2006.

SANTOS, M.L.; STEVAUX, J.C.; GASPARETTO, N.V.L.; SOUZA FILHO, E. E. Geologia e geomorfologia da planície aluvial do rio Ivaí em seu curso inferior. Revista brasileira de Geomorfologia, v.9, n.1, p. 23 - 34, 2008.

SANTOS, M.L.; KUERTEN, S.; GASPARETTO, N.V.L. Variação longitudinal da hidrodinâmica, morfologia do canal e carga sedimentar do baixo curso do rio Ivaí - Paraná, Brasil. In: V Congresso Nacional de Geomorfologia, Porto. Volume de actas/ proceedings do V Congresso Nacional de Geomorfologia. Porto: Associação Portuguesa de Geomorfologia, v. 1, 2010. p. 151-156.

SOUZA, M.L.; GASPARETTO, N.V.L.; NAKASHIMA, P. Diagnóstico geoambiental da bacia do córrego Tenente em Mariluz, Paraná, Brasil. Revista Brasileira de Geociências. v. 38, n. 2, p. 379-391, 2008.

THORNTHWAITE, C.W.; MATHER, J.R. The water balance. Pubs. Clim. Drexel-Inst. Technol, Centerton, v. 8, n. 1, p. 1-104, 1955.

VALERIANO, M.M.; ROSSETTI, D.F. Topodata: Brazilian full coverage refinement of SRTM data. Applied Geography (Sevenoaks) v. 32, p. 300-309, 2011. 